\title{
Historiando a mim mesmo: \\ mo(vi)mentos de uma pesquisa autobiográfica e narrativa
}

Luiz Carlos Pinheiro Ferreira ${ }^{i}$

\section{Resumo}

O texto, de caráter autobiográfico e com ênfase em fragmentos narrativos, apresenta recorte da pesquisa de doutorado, concluída no Programa de Pós-Graduação em Arte e Cultura Visual da Faculdade de Artes Visuais da Universidade Federal de Goiás. Os resultados parciais estão organizados em mo(vi)mentos de investigação, numa perspectiva biográfico-narrativa que olha e analisa aspectos da vida pelo espelho retrovisor, construindo reflexões acerca de momentos da minha trajetória de vida e da minha atuação como docente no Departamento de Artes Visuais da Universidade de Brasília. A pesquisa de campo foi realizada com alunos-colaboradores do Curso de Licenciatura em Artes Visuais da referida universidade.

\section{Palavras-chave}

autobiografia, narrativa, experiência, artes visuais.

\section{"Historycizing" myself: \\ Moments/movements of an autobiographical and narrative research}

\begin{abstract}
The text, of autobiographical character and with emphasis in narrative fragments, presents part of a doctoral research concluded in the Art and Visual Culture Graduate Program of the Faculty of Visual Arts at the Federal University of Goiás, Brazil. The partial results are organized in research moments/movements in an autobiographical narrative that focus life aspects through a rear mirror, constructing reflections about moments of my life trajectory and my teaching practice in the Visual Arts Department at the University of Brasilia, Brazil. The fieldwork was developed with student's collaborators of the Visual Arts Teacher Training Program of the referred university.

Keywords

autobiography, narrative, experience, visual arts
\end{abstract}

\section{Mo(vi)mentos de uma pesquisa autobiográfica e narrativa}

O texto sinaliza aspectos/momentos de um olhar pelo espelho retrovisor da vida com o intuito de conceber pelo viés autobiográfico e narrativo da pesquisa, uma retomada de questões acerca de "alguns" mo(vi)mentos que foram determinantes para o processo formativo e autoformativo na minha história de vida. O estudo parte dessa retro(re)visão e é construído a partir de momentos de inquietação e questionamento, tanto das escolhas que me movimentaram para o caminho da pesquisa acadêmica, quanto na experiência docente no âmbito do curso de Licenciatura em Artes Visuais da Universidade de Brasília, instituição onde exerço esta função desde 2009.

Aponto algumas reflexões que foram determinantes para o surgimento das ideias que levaram-me a considerar a expressão mo(vi)mento como alternativa para caracterizar os capítulos da tese de doutorado. Posteriormente, apresento um recorte de dois momentos 
da investigação a partir de aspectos específicos. O primeiro, aborda o estudo relacionado à vivências e experiências, trazendo a prerrogativa de "historiar a mim mesmo" como caminho para o conhecimento de si. No segundo momento, articulo teoricamente uma experiência pedagógica vivenciada e desenvolvida durante a pesquisa de campo com alunos-colaboradores do Curso de Licenciatura em Artes Visuais.

\section{Momentos + movimentos $=\mathbf{m o}(\mathbf{v i})$ mentos de investigação}

Ao trazer a expressão mo(vi)mento para pensar o contexto de uma pesquisa autobiográfica e narrativa, torna-se necessário explicitar a razão pela qual a utilizo com o intuito de promover uma ação que parte de "momentos com movimentos", o que determinou no contexto da pesquisa uma possibilidade de justaposição que resultou em mo(vi)mentos de pesquisa. Tal justaposição, gestada para constituir os capítulos da tese, sobrevém do desejo pelo conhecimento de si, da necessidade de avançar e dos momentos\&movimentos que fazem parte da minha construção como sujeito.

A busca pelo "conhecimento de si" (SOUZA, 2006), decorre dos rememoramentos provenientes das experiências e aprendizagens vivenciadas ao longo da minha trajetória de vida, principalmente, no contexto da escolarização e do exercício da profissão docente. Esses rememoramentos, experiências e aprendizagens, funcionam como vozes polifônicas que, segundo Bakhtin (2004), atravessam o sujeito confrontando-o e chamando-o à reflexão sobre as experiências constituídas através da linguagem, sobretudo, ao buscar um argumento para corroborar com as questões relacionadas aos momentos e movimentos de uma pesquisa, suas experiências e aprendizagens, assim como a polifonia de vozes presentes no sujeito. No caminho, encontro em Souza (2006) ressonância para pensar que o processo de falar de si para si mesmo, como um conhecimento de si, permite ao sujeito organizar a sua narrativa através de constante diálogo interior, através do processo de formação e de conhecimento porque o aprendizado e o conhecimento de si não acontecem sem o aprendizado dos contratempos e intempéries da vida, cuja condição é importante para o acesso a realidade dialética, seu devir presentificado num processo permanente de formação e autoformação.

Nesse encontro com o conhecimento de si, apontado por Souza (2006), reside o intuito de promover fragmentos narrativos relacionados com os processos formativos e autoformativos presentes nos momentos que caracterizam o percurso da vida, vinculados às demandas e necessidades de avançar e movimentar-me provocando mo(vi)mentos e inquietações necessários para que a pesquisa pudesse acontecer. Foi a partir dessas inquietações que iniciei esse diálogo prazeroso e ao mesmo tempo carregado de conflitos 
com a expressão mo(vi)mento, combinando justaposições, associações e sentidos que (des)velassem demandas presentificadas nas lembranças da infância.

A lembrança, segundo Souza (2007), remete o sujeito a observar-se numa dimensão genealógica, ou seja, num processo de recuperação do eu em busca de suas origens, dos acontecimentos que marcaram sua memória. Souza acrescenta que a memória, em sua dimensão narrativa, "como virada significante, marca um olhar sobre si em diferentes tempos e espaços, os quais se articulam com as lembranças e as possibilidades de narrar experiências" (SOUZA, 2007, p. 63). Desse olhar sobre si, conforme explica Souza, procuro subsídios para encontrar fragmentos narrativos das experiências marcantes na época da infância. Acrescento, ainda, que ao encontrar os caminhos narrativos provenientes das experiências da infância, outras trilhas surgirão, provavelmente, relacionados com os mo(vi)mentos do meu processo de formação e autoformação.

Ao invocar determinadas cenas guardadas na memória, ainda de acordo com Souza (2007), devemos atentar que ela não se fixa apenas no campo subjetivo, mas, situa-se num contexto histórico e cultural, sendo, também, uma experiência histórica indissociável das experiências peculiares de cada indivíduo e de cada cultura. A memória, como uma experiência histórica, estaria, então, na fronteira entre passado e presente, entre aquilo que foi experienciado e vivenciado. Nesse aspecto, torna-se relevante pensar a busca do conhecimento de si a partir de rememoramentos, das experiências cotidianas vivenciadas nesse espaço-tempo histórico do passado como caminho para encontrar possíveis respostas. Respostas atreladas à momentos\&movimentos decisivos da minha vida. Respostas que podem dar conta do desejo pelo conhecimento que me instiga a avançar.

Nesse sentido, foi relevante justapor uma palavra a outra, como meio de provocar fissuras e abrir brechas que contribuam, fundamentalmente, na construção dos meus desejos, histórias e perspectivas de vida. No exercício de montagem desse quebracabeça, um exercício de elaboração, surgiu a palavra momento. Ao trazer essas duas palavras para o contexto da pesquisa, pondero que a liberdade concedida na justaposição entre uma e outra, almeja uma possibilidade semântica para justificar que, foram os momentos vividos que possibilitaram a elaboração de ensaios, levando-me à reflexão e ponderação dos movimentos necessários para avançar.

A justaposição das palavras promoveu um encontro de sentidos para dar conta daquilo que pretendo estabelecer como meio de construção da minha narrativa de vida e de pesquisa: a relação entre experiências e vivências. Essa relação ganha amplitude e 
potência quando somada às possibilidades de interrogar o passado a partir do conhecimento adquirido no presente.

\section{Primeiro momento:}

\section{historiando a mim mesmo a partir de experiências e vivências}

Investigo na proposição de Santos (2007), quando afirma que "todo conhecimento é autoconhecimento" (p. 50), uma possibilidade de compreender que na minha experiência e vivência como sujeito tenho realizado mo(vi)mentos no caminho da construção desse conhecimento, com a expectativa de que os investimentos, a produção e a própria construção desse conhecimento produzam autoconhecimento. Autoconhecimento como forma de compreender minha posição como sujeito, como professor e como indivíduo que habilita uma relação com o mundo da experiência que, segundo Dilthey (2010), confere aos acontecimentos da vida uma expressão mais densa e reflexiva sobre a mesma.

A construção desse conhecimento se fez e ainda se faz a todo momento, durante o exercício da profissão docente e, agora, se intensificou a partir do processo de doutoramento que considera, entre outras coisas, experiências vividas no contexto da minha trajetória de escolarização, formação e atuação no campo das Artes Visuais. Essas vivências levam-me ao resgate de lembranças guardadas na memória, episódios que foram marcantes e pontuais para definir meu envolvimento com a profissão docente. Envolvimento marcado, especialmente, pela construção de conhecimento.

Ao buscar a produção desse conhecimento não posso deixar de considerar e rememorar experiências que foram vivenciadas ao longo da minha formação como sujeito, como professor e como indivíduo desejante. Essas experiências, especialmente aquelas presentificadas em episódios singulares, vividos na infância, foram determinantes para a minha sobrevivência. Sobrevivência da alma, para além do corpo, que alimentou esse "desejo de saber e de viver" a partir de situações corriqueiras, porém, impregnadas de uma força criativa que desencadeou, mesmo que inconscientemente, uma relação intensa com a vida, recheada por reminiscências visuais que dizem respeito ao processo autorreferencial e a escrita. Em consonância com Souza (2006), entendo que essas reminiscências estão implicadas em:

[...] formas textuais de dizer de si e sobre si mesmo, num constante diálogo entre a esfera do vivido e as fertilidades formativas e autoformativas das experiências e das transformações de identidade e subjetividade no processo de formação docente. (p. 13) 
Com essa perspectiva acerca das demandas textuais de dizer de si e sobre si mesmo, cabe ressaltar a necessidade de pensar uma abordagem experiencial e existencialista que privilegie o sujeito, sua identidade e subjetividade. Esse pensar pode ser entendido e implicado na produção de uma realidade formativa e reflexiva, do âmbito da vida com situações compartilhadas, ao conceber e compreender que o processo de construção do conhecimento e de autoconhecimento está alicerçado nos mo(vi)mentos trazidos do cotidiano para o âmbito reflexivo da formação e da necessidade do conhecimento de si.

Nesse sentido, os conceitos que transitam entre experiência, vivência, conhecimento e autoconhecimento, a formação e a autoformação, o conhecimento de si e as narrativas, são relevantes para os mo(vi)mentos da pesquisa, sobretudo, numa perspectiva dialógica entre a esfera do vivido e do experienciado. Souza (2007) destaca que "o pensar em si, falar de si e escrever sobre si mesmo emergem em um contexto intelectual de valorização da subjetividade e das experiências privadas" (p. 68).

No sentido apontado por Souza, a escrita de si, particularmente, tende a reformar minha relação com o conceito e entendimento do mundo, numa perspectiva que coloca a experiência "privada" como mote para repensar cenas vividas durante a época de infância. A figura 1 representa um momento da infância no qual o desafio de "pular o muro e conhecer outra casa era desafiador. Essa aventura significava uma ousadia que, inconscientemente, nutria meu desejo de sair dos limites do mundo da casa. Ao experimentar esse outro mundo representado pela casa ao lado, passei a ter contato com uma estante repleta de livros. Dona Lenir, nossa vizinha, gostava de ler para $\operatorname{mim} . . .11$.

\footnotetext{
${ }^{1} \mathrm{O}$ trecho apresentado entre aspas refere-se a um dos inúmeros fragmentos narrativos utilizados no decorrer da tese de doutorado, com o objetivo de referendar episódios, cenas e momentos relevantes vividos durante a trajetória de vida.
} 


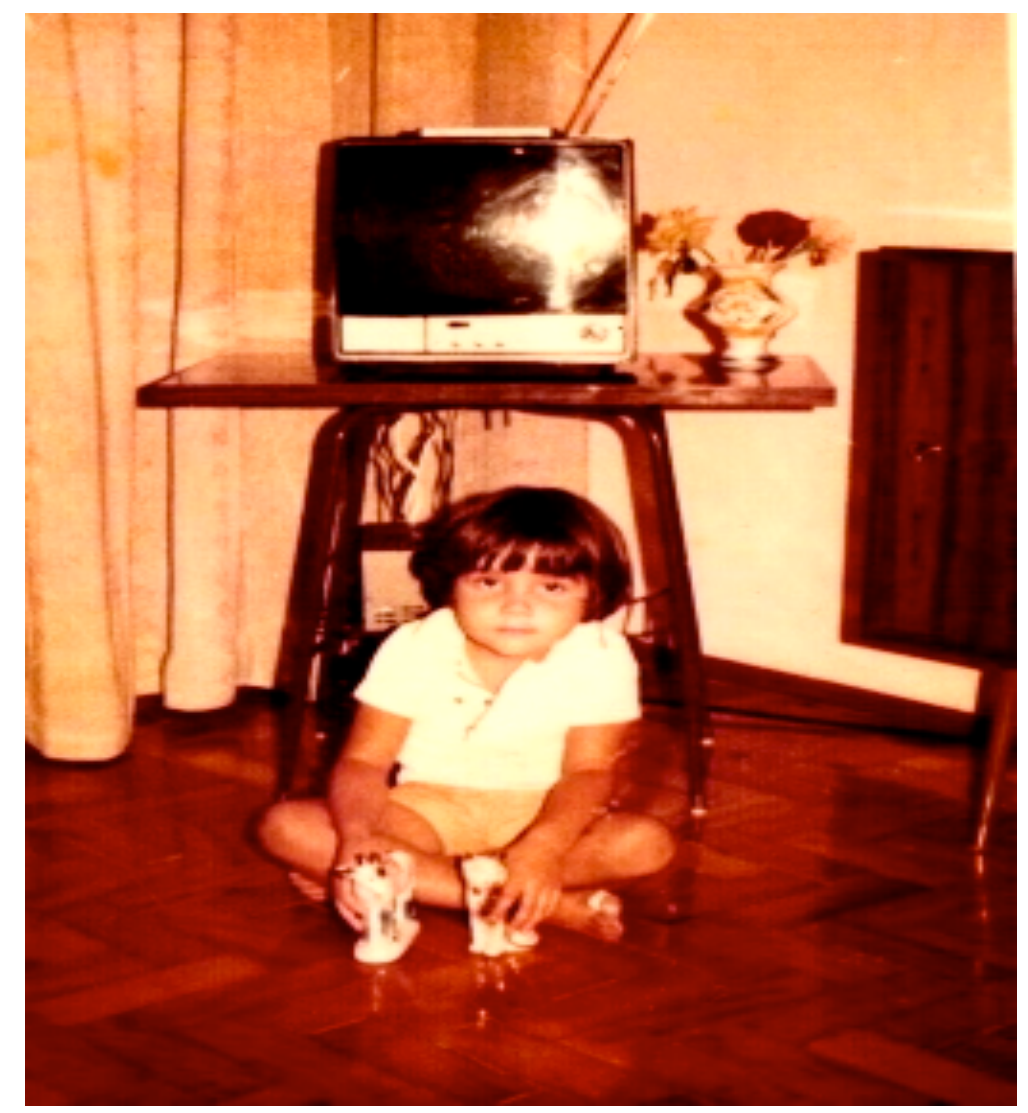

Figura 1: Foto tirada pelo filho de Dona Lenir. Momento de brincar e de ouvir estórias. Acervo particular do autor.

A experiência que vivi a partir do contato com a narrativa das estórias infantis contadas por Dona Lenir, configurou em mim marcas, interesses e motivações relevantes no tocante à minha vida na infância. Clandinin e Connelly (2011) consideram fundamental o processo da narrativa como uma maneira de compreender a experiência. Experiência que pode ser vivenciada na escola, em meio a outras crianças, em outros espaços, em outros processos, com outros sujeitos, em outros mundos.

Olhando para a infância, vejo-me sentado no chão próximo à televisão na casa de Dona Lenir, pronto para ouvir pacientemente as estórias que ela contava. Percebo que esse momento de experiência no mundo da casa ao lado foi representativo em termos da narrativa. Lembranças da voz de dona Lenir, do cheiro da casa e o desafio de estar ali ficaram impregnadas na minha subjetividade da infância. De acordo com Sanches (2010), a "narrativa faz essa mediação reflexiva: proporciona, por meio de uma subjetividade que se faz no tempo, enfrentando as vicissitudes da vida, uma identidade 
pessoal narrativizada e reflexiva, que não se esconde do mundo (p. 112). A narrativa é uma urdidura da dinâmica subjetiva de quem conta, como conta e onde conta. As instâncias do tempo, da vida, tinham um sentido atemporal na minha percepção de criança. Os momentos importantes eram aqueles destinados as coisas prazerosas: comer o danoninho, brincar com os pés do meu pai, pular o muro para ouvir as estórias da Dona Lenir, ver minha mãe fazer bolo e pudim, coisas que ficaram na lembrança de criança e que não se escondem do mundo.

A medida que fui experimentando outras estórias com Dona Lenir, meu pensamento floresceu e passei a cultivar o hábito de desenhar. Como não sabia escrever o desenho era o modo de expressar minha imaginação acerca dos mundos que imaginava. A cada desenho, novos mundos eram criados, criando laços com a minha existência, a minha vida, com os medos e anseios acerca do mundo imaginado e desconhecido. Segundo Dilthey (1992), nesse tipo de contexto, nasce o sentido da experiência da vida. O autor acrescenta que:

o fundo de que parte todo o pensar e agir humano é a vida: inconcebível, inexplicável, impérvia ao conceito ou pelo conceito, ela é essencialmente pluralidade de aspectos, transição para opostos reais, luta de forças; é um processo de diversificação e de diferenciação que se desdobra em experiências inéditas. É próprio da vida manifestar-se e objectivar-se em símbolos, suscitar mundos, pois todo o dentro busca expressão num fora. Eis porque ela surge como a raiz última da mundividência. (p.10)

Compreendo que a experiência da vida é única. Esse pensar e agir humano, conforme explica Dilthey, é algo intransferível, inseparável e próprio do sujeito. As experiências são únicas, porque a relação com a vida ocorre pelas reentrâncias dos acontecimentos, nesse olhar pelo espelho retrovisor que percorre passado e presente em busca de sinais. A atuação contínua do passado estabelece força no presente, o que desencadeia uma busca por respostas, por ações que foram determinantes na vivência do sujeito, ou seja, pular o muro e buscar por aquilo que na minha memória de hoje representa o frescor da lembrança de infância: ouvir a leitura do livro. Encontrei um mundo diverso do meu onde o acesso a outros mundos imaginários fez despertar o meu desejo pelo conhecimento. Dividido entre o mundo de casa e o mundo que me convidava para aprender, não resisti. Trilhei o caminho do aprender, reportando-me ao processo do aprendizado pela experiência, por aquilo que nos passa, acontece e toca (LARROSA, 2002). O pular o muro, experimentar o livro, vivenciar um outro mundo foram momentos marcantes da infância. Acredito que essas experiências e vivências ainda passam, acontecem e tocam sutilmente minha tessitura de sujeito. 
A busca pelo conhecimento de si inscreve-se na esfera de um lugar que está fora do sujeito, um lugar como possibilidade de transformação e autotransformação (SOUZA, 2006), elaborativo e reflexivo perante as memórias de infância e as vicissitudes da vida. Esse lugar inscreve-se nos acontecimentos da vida. Dilthey (2010) enfatiza que "as autobiografias são a expressão mais direta da reflexão sobre a vida" (p. 176), justamente por considerar que para escrever uma autobiografia, o sujeito precisa entender as conexões que fizeram parte do seu transcurso vital de existência, ou seja, sua história. Dilthey cita os exemplos de Agostinho, Rousseau e Goethe como formas históricas típicas da expressão mais direta que pode envolver as reflexões autobiográficas sobre a vida.

\section{A narrativa como caminho de pesquisa}

Clandinin e Connelly (2011) apontam que, "a pesquisa narrativa é uma forma de compreender a experiência" (p. 51), portanto, o que surge no contexto das experiências vivenciadas é fruto do desenvolvimento de ações corriqueiras, aquelas a que estão submetidas nossos fazeres\&dizeres cotidianos. Para os autores, a pesquisa narrativa é uma forma de compreender a experiência. Então, posso dizer que a experiência vivencial do sujeito é caminho percorrido e a percorrer através de narrativas. Desse ponto de vista, como mote para compreender o cotidiano e as ações que fazem do sujeito um ser social, histórico e cultural, busco interlocução com Souza (2006), por entender que o seu movimento de pesquisa, realizado no âmbito das investigações de doutorado, privilegiou o processo de investigação-formação com uma abordagem biográfica como perspectiva epistemológica, pensando a aprendizagem dos sujeitos a partir das suas próprias experiências. Ele aborda o conhecimento de si como um método de análise e compreensão das implicações e das narrativas presentes no processo de formação e autoformação dos sujeitos. Assim, posso afirmar que a experiência vivencial dos sujeitos envolvidos na pesquisa também percorre um caminho narrativo.

Desse modo, ao refletir sobre as lembranças da infância, das memórias presentificadas no mundo da casa e das narrativas construídas a partir daquilo que foi vivido e experienciado na minha prática docente, percebo quão importante foi o processo que me constituiu, tanto no aspecto da minha formação quanto no tocante à minha autoformação como sujeito. As considerações de Souza são pertinentes para arregimentar argumentos que construam outros diálogos acerca do sujeito e do processo do conhecimento de si orientado por narrativas que aportem experiências marcantes, inscritas na minha tessitura de vida, porque

a escrita da narrativa remete o sujeito a uma dimensão de autoescuta, como se estivesse contando para si próprio suas 
experiências e as aprendizagens que construiu ao longo da vida, através do conhecimento de si. E com base nessa perspectiva que a abordagem biográfica instaura-se como um movimento de investigação-formação, ao enfocar o processo de conhecimento e de formação que se vincula ao exercício de tomada de consciência, por parte do sujeito, das itinerâncias e aprendizagens ao longo da vida, as quais são expressas através da metarreflexão do ato de narrar-se, dizer-se de si para si mesmo como uma evocação dos conhecimentos construídos nas suas experiências formadoras. (SOUZA, 2006, p.14)

A pesquisa de Souza remete ao processo de investigação-formação e autoformação de sujeitos, processo que me interessa pelo aspecto biográfico, ao considerar que os sujeitos estão implicados num mecanismo de auto-escuta a partir da sua escrita narrativa. Essa escrita imbrica-se num processo permanente de rememorar, de deixar vir à tona algo que completa o sujeito e permite à compreensão de situações, de histórias, de momentos e episódios guardados na memória, delineando que o "[...] ato de narrar tem como propriedade o estabelecimento de percepções confiáveis da memória" (GINZBURG, 2012, p. 116).

Por esta razão, o campo da memória ganha reconhecimento por representar arcabouço "confiável" que privilegia os encontros entre aquilo que busco nos meandros da minha trajetória de vida, como forma de presentificar o processo de constituição do sujeito e, ainda, o processo de conhecimento de si através da narrativa, entendida aqui como "[...] o melhor modo de representar e entender a experiência" (CLANDININ e CONNELLY, 2011, p. 48)

Sem o processo da experiência como arcabouço para representar e entender o que sou, o que quero ser e, inevitavelmente, o que fui num passado distante, seria impossível considerar, conforme aponta Souza, a dimensão da auto-escuta que promove o encontro entre esse "eu" que conta para si mesmo suas experiências e sua memória. Experiências carregadas de histórias, vividas e contadas, que no contexto da Educação permitem um entendimento acerca da vida e da formação.

Ao abordar a experiência como processo pertinente ao contexto das histórias vividas e contadas, os estudos de Clandinin e Connelly (2011) concentram-se no campo conhecido como pesquisa narrativa. Esse campo, segundo Martins e Tourinho (2009), a partir dos anos 80 tornou-se tema de interesse acadêmico, repercutindo nos departamentos de literatura, psicologia e sociologia. Os autores alertam para o fato que, na última década, a pesquisa narrativa expandiu-se para áreas como a cultura, educação, cinema, teatro e artes visuais e, desse modo, "aos poucos, a narrativa vem se tornando objeto de estudo, ganhando espaço em diferentes disciplinas, influenciando a prática da pesquisa e, 
consequentemente, os debates acadêmicos" (p. 1). Essa perspectiva, que leva em conta a disseminação da pesquisa narrativa para outras áreas, visa contribuir para o deslocamento de olhares que ainda acreditam na neutralidade do sujeito na produção do conhecimento ignorando a dimensão subjetiva presente e atuante na percepção da realidade e dos fatos.

Para Clandinin e Connelly (2011), estudos de pesquisa narrativa tem avançado em notoriedade e confiabilidade no mundo da pesquisa qualitativa, justamente, por assegurar a captura das dimensões pessoais e humanas que, de algum modo, não podem ser quantificadas como fatos e dados numéricos. Os fatos e dados perfazem um contexto de vida assegurando que o sujeito torne-se, ao mesmo tempo, sujeito e objeto da pesquisa, considerando inclusive as subjetividades inerentes ao processo.

\section{Segundo momento:}

\section{a experiência pedagógica como reconhecimento de si}

Pensar a vida, a formação e a prática docente a partir de fragmentos narrativos, pressupõe considerar a pesquisa como produção de conhecimento ao tratar da complexidade que envolve os domínios social, cultural, psicológico e educacional (KINCHELOE, 2007). Nessa sintonia, entendo também que a compreensão acerca da realidade existencial confere um conhecimento autoimplicativo, ou seja, um modo de conhecer hermenêutico que, ao mesmo tempo em que amplia o conhecimento das coisas, também proporciona um saber sobre nós mesmos (SOUZA e FORNARI, 2012). De acordo com o pensamento dos autores, o processo metodológico da pesquisa deve contemplar episódios pedagógicos ocorridos em sala de aula. Episódios que apontem de forma peculiar um modo de conceber o conhecimento a partir de reflexões acerca do cotidiano, da vida e das experiências pessoais. Nesse sentido, tomo como referência um dos episódios analisados durante a pesquisa de campo, com o intuito de apresentar sinteticamente alguns dados produzidos na investigação.

O exemplo apresentado tenciona uma abertura para processos que envolvem aprendizagem e reflexividade sobre a vida e suas vicissitudes, sobretudo ao considerar os escritos de Passeggi, Souza e Vicentini (2011) como respaldo para compreender que "essa busca da história de vida do outro ultrapassa os limites da curiosidade gratuita para se tornar uma busca de padrões de comportamento" (p. 371). A questão apontada pelos autores pautou minhas reflexões durante a pesquisa de campo ${ }^{2}$ ao descrever a

\footnotetext{
${ }^{2}$ A pesquisa de campo foi realizada no período entre o segundo semestre de 2011 e o primeiro semestre de 2013, com alunos colaboradores do Curso de Licenciatura em Artes Visuais da Universidade de Brasília.
} 
narrativa ${ }^{3}$ que trata o episódio pedagógico sobre a Cultura do Gagaísmo. O tema foi proposto por duas alunas do curso de Licenciatura em Artes Visuais na apresentação de um seminário para a disciplina de Elementos de Linguagem, Arte e Cultura Popular, sob minha responsabilidade, oferecida no segundo semestre letivo de 2010. Uma das alunas é fascinada pela imagem e personalidade da artista pop Lady Gaga.

Ao propor aos alunos a apresentação de seminários relacionados ao tema Cultura, meu objetivo era priorizar diferentes abordagens e pesquisas que contemplassem um panorama amplo a respeito do conceito de cultura, para além daquilo que eu e a turma, assim pensava, poderíamos esperar. Foi considerável a diversidade de temas e propostas pelos alunos, entre elas, a "Cultura do Gagaísmo". Aparentemente inusitado no contexto acadêmico, o tema apresentava claramente questionamentos, vínculos e aproximações relacionados ao termo cultura, inclusive, quando associado à "Cultura do Gagaísmo". A proposta da aluna para apresentar o seminário focava um tipo de cultura pop midiática expressa nos videoclipes da cantora Lady Gaga e no ritmo da música que, na época, fazia muito sucesso. Uma das alunas colaboradoras da pesquisa, denominada Castelar, é extremamente fascinada pela artista pop Lady Gaga. Castelar nomeia-se LeeGaga e faz apresentações em boates GLS de Brasília, atua como uma espécie de "cover" da Lady Gaga e se intitula uma "Gagaísta de carteirinha", justamente por pertencer ao fã clube de Lady Gaga e defender seus mandamentos. (Figura 2)

\footnotetext{
${ }^{3}$ A narrativa sobre a Cultura do Gagaísmo foi apresentado no IV Seminário Nacional de Pesquisa em Arte e Cultura Visual realizado pelo Programa de Pós-Graduação da Faculdade de Artes Visuais da Universidade Federal de Goiás (FAV/UFG) em junho de 2011.
} 


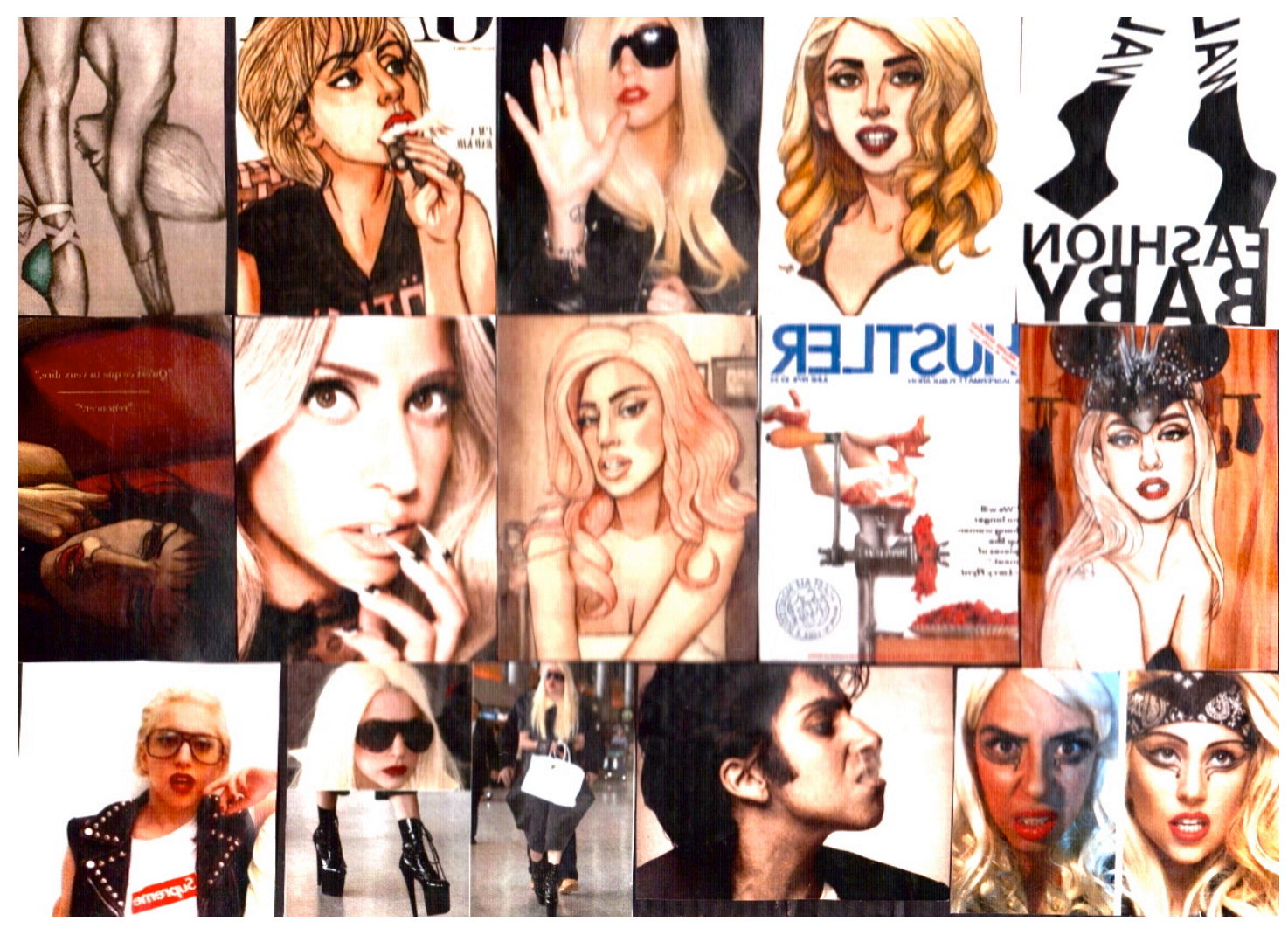

Figura 2: Colagem produzida pela colaboradora da pesquisa.

A colagem projeta a relação com a cantora Lady Gaga e suas múltiplas identidades.

Trabalho doado para a pesquisa. Acervo particular do autor.

A imagem representa o trabalho de colagem realizado por Castelar. Fica evidente, na colagem apresentada pela colaboradora, uma aproximação e interesse pela identidade da artista Lady Gaga. Essa aproximação reforça o conceito de pensar "a história de vida do outro" como um padrão de comportamento, ou mesmo, numa perspectiva heteroformativa (PASSEGGI, 2008), considerando sua relação com o outro, ou ainda, uma espécie de heterobiografia (DELORY-MOMBERGER, 2009; 2008), ou seja, a imposição de modelos biográficos e a própria vida da pessoa. Na colagem são usadas imagens e alguns fragmentos que representam a cantora Lady Gaga, mas, também, uma imagem de Castelar, na parte inferior direita (quinta imagem entre John Calderoni e Gaga). Essa inclusão gera uma semelhança entre a caracterização de Lady Gaga e da própria Castelar, atitude que denota o intuito de misturar-se com as diferentes personas de Lady Gaga.

Na pesquisa de campo, ao propor entrevistas individuais com base em fatos e dados relacionados à experiência pedagógica na qual são considerados fragmentos narrativos advindos da vida e da história do sujeito, fica explícita a compreensão de que os 
fragmentos apresentados fazem parte do mundo dos fatos. De acordo com Passeggi, Souza e Vicentini (2011),

a escrita de relatos autobiográficos dá aos indivíduos a possibilidade de articular, por meio das narrativas que produzem sobre si, as "experiências referenciais" pelas quais passaram, dotando a própria trajetória profissional de sentido. (p. 378)

Neste caso, posso citar como exemplo circunstancial, trecho de uma entrevista realizada com a aluna-colaboradora, cujo relato reproduzo aqui como um dos fragmentos narrativos:

\begin{abstract}
Eu sou Castelar dos dezesseis mundos. Certa vez falei isso para a minha terapeuta e ela ficou me questionando sobre essa questão dos dezesseis mundos. O que seriam esses mundos? Eu falei que como faço muita coisa, preciso dar conta de muita coisa, às vezes me sinto fora da minha própria identidade de Aline. Então, resolvi eleger essa história/estória de dezesseis mundos para poder explicar para as pessoas quem eu sou em determinados momentos. Quando estou fazendo cover da Lady Gaga eu sou LeeGaga, como uma irmã, quando estou dando aula de português eu sou a LeeProfessorinha, inspirada em professores que tive no colégio, quando estou em casa eu sou a LeeFilha e, assim por diante, eu vou elegendo mundos nos quais eu preciso transitar. Isso é para poder sobreviver nesse mundo cão. (Entrevista realizada com Castelar em 16/11/2011)
\end{abstract}

Esse fragmento da entrevista põe em perspectiva aspectos do contexto do curso de Licenciatura em Artes Visuais como parte da interação de Castelar com o mundo. Ela percebe e sente a sua vida rodeada por circunstâncias que a fazem acionar criativamente um mecanismo para dar conta do seu mundo cão. Para Castelar, falar da diversidade desse mundo pressupõe construir "experiências referenciais" que são atribuídas aos diferentes momentos da sua vida. No entanto, essa diversidade de representações não impede que ela dê sentido à sua trajetória, mesmo que fragmentando-a.

Ao apontar fatos da sua realidade pessoal, social e profissional, Castelar explicita algo que, de acordo com Clandinin e Connelly (2011) representa um "fragmento narrativo". Ela constrói uma relação intrínseca com os seus dezesseis mundos, articulando a dimensão expressiva da narrativa ou, dizendo melhor, do próprio fragmento narrativo. Os mundos de Castelar estão relacionados com o mundo de Lady Gaga. Ao falar sobre os mundos, Castelar busca similaridades com o mundo de Lady Gaga, porém, na construção da fala, estabelece um mundo paralelo, pois não ousa copiar o mundo de Lady Gaga. A dimensão expressiva fica evidente quando Castelar fala de LeeGaga como se fosse uma irmã de Lady Gaga e não a sua cópia. 
De acordo com Delory-Momberger (2012), essa busca pela história do outro reside naquilo que a autora chama de "heterobiografia", uma espécie de constitutivo da condição biográfica na modernidade avançada. Essa condição situa o individuo entre a imposição de modelos biográficos e o gerenciamento da própria vida. A imposição de modelos biográficos resulta da disseminação de ideias e valores somados ao próprio modo de conceber a vida.

Essa concepção de vida, ao se misturar com outras referências, gera um processo de aprendizagem que considera os atos de ver, conhecer, ouvir e ler sobre o outro como condicionante para a criatividade humana. Por sua vez, a criatividade humana é capaz de reinventar e reconstituir a consciência histórica através de aprendizagens vivenciadas ao longo da vida, levando em conta as referências e a produção de sentidos como forma de reflexão perante a própria vida.

\section{Narrativas: o contar e recontar de uma história}

Ao (re)contar esse momento da pesquisa e (re)visitar a experiência pedagógica sobre a Cultura do Gagaísmo, percebo quão relevantes são as histórias de vida, capazes de alimentar um desejo pela própria vida, pela expectativa de buscar situações novas, possibilidades de transformar a existência em produção de sentidos. Em sintonia com o pensamento de Clandinin e Connelly, podemos dizer que "na construção de narrativas de experiências vividas, há um processo reflexivo entre o viver, contar, reviver e recontar de uma história de vida" (CLANDININ e CONNELLY, 2011, p. 108). Esse processo me leva a compreender que o movimento realizado no contexto das estórias\&histórias imaginárias e vivenciadas em determinado período da vida, tanto no processo biográficonarrativo compreendido através da minha trajetória, quanto na percepção das trajetórias que vivenciei ao longo das entrevistas com os colaboradores da pesquisa, me faz considerar a potencialidade reflexiva do relato narrativo. Essa potencialidade promove uma percepção sobre a vida, como também por aquilo que esperamos da vida, pelo sentido dos mo(vi)mentos que nos impulsionam a percorrer os caminhos intrínsecos ao próprio processo de viver uma vida.

\section{Referências}

BAKHTIN, Mikhail. Marxismo e filosofia da linguagem. Problemas fundamentais do Método Sociológico nas Ciências da Linguagem. Tradução: Michel Lahud \& Yara Frateschi Vieira. São Paulo: Editora Hucitec, 2004.

CLANDININ D. Jean e CONNELLY, F. Michael. Pesquisa Narrativa: experiência e história em pesquisa qualitativa. Tradução: Grupo de Pesquisa Narrativa e Educação de Professores ILEEL/UFU. Uberlândia: EDUFU, 2011.

DELORY-MOMBERGER, Christine. Abordagens metodológicas na pesquisa biográfica. Revista Brasileira de Educação. v.7, n. 51, p. 523-536, setembro-dezembro, 2012. < 
Disponível em: http://www.scielo.br/pdf/rbedu/v17n51/02.pdf Acesso em: $10 / 09 / 2013>$

DELORY-MOMBERGER, Christine. La condition biographique: essais sur le récit de soi dans la modernité avancée. Paris: Téraèdre, 2009.

DELORY-MOMBERGER, Christine. Biografia e Educação. Figuras de l'individuo-projeto. Tradução: Maria da Conceição Passeggi, João Gomes Neto, Luis Passeggi. São Paulo: Paulus; Natal, RN: EDUFRN, 2008.

DILTHEY, Wilhelm. A construção do mundo histórico nas ciências humanas. Tradução: Marco Casanova. São Paulo: Editora UNESP, 2010.

DILTHEY, Wilhelm. Teoria das concepções do mundo. Tradução: Artur Morão. Rio de Janeiro: Edições 70, 1992.

GINZBURG, Jaime. A interpretação do rastro em Walter Benjamin In: SEDLMAYER, Sabrina e GINZBURG, Jaime (Org.). Walter Benjamin: rastro, aura e história. Belo Horizonte: Editora UFMG, 2012, p. 107-132.

KINCHELOE, Joe. Questões de disciplinaridade/interdisciplinaridade em um mundo em transformação. In: KINCHELOE, Joe L. \& BERRY, Kathleen S. Pesquisa em educação: conceituando a bricolagem. Tradução: Roberto Cataldo Costa. Porto Alegre: Artmed, 2007, p. 67-99.

LARROSA, Jorge. "Notas sobre a experiência e o saber de experiência" Traducão: João Wanderley Geraldi. In: Revista Brasileira de Educação. No 19, Jan/Fev/Mar/Abr, Rio de Janeiro, ANPED, 2002, p. 20-28.

< Disponível em: http://www.scielo.br/pdf/rbedu/n19/n19a02.pdf Acesso em: $10 / 09 / 2013>$

MARTINS, Raimundo; TOURINHO, Irene. Pesquisa Narrativa: concepções, práticas e indagações. In: Anais do II congresso de educação, arte e cultura - CEAC, Santa Maria, 2009, p. 1-12.

PASSEGGI, Maria da Conceição. Memoriais: injunção institucional e sedução autobiográfica. In: PASSEGGI, Maria da Conceição e SOUZA, Elizeu Clementino de. (orgs.) (Auto)Biografia: formação, territórios e saberes. Natal, RN: EDUFRN; São Paulo: Paulus, 2008.

PASSEGGI, Maria da Conceição; SOUZA, Elizeu Clementino de; VICENTINI, Paula Perin. Entre a vida e a formação: pesquisa (auto)biográfica, docência e profissionalização. Educação em Revista: Belo Horizonte, v. 27, n. 01, p. 369-386, abril, 2011 . < Disponível em: http://www.scielo.br/pdf/edur/v27n1/v27n1a17.pdf Acesso em: $19 / 05 / 2013>$

SANCHES, Roberto. O saber da narração: Paul Ricoeur e Marie-Christine Josso. In: ABRAHÃO. Maria Helena Menna Barreto (org.) (Auto)biografia e formação humana. Porto Alegre: EDIPUCRS, 2010.

SANTOS, Boaventura Sousa. Um discurso sobre as ciências. Porto, Portugal: Edições Afrontamento, 2007.

SOUZA, Elizeu Clementino de. e FORNARI, Liege Maria Sitja. Memória, (Auto)Biografia e Formação. In: VEIGA, Passos Alencastro e D'ÁVILA, Cristina Maria (org.) Profissão docente: novos sentidos, novas perspectivas. Campinas, São Paulo: Papirus, 2012, p. 109-134. 
SOUZA, Elizeu Clementino de. (Auto)biografia, história de vida e práticas de formação In: NASCIMENTO, HETKOSWKI, (orgs). Memória e formação de professores [online] Salvador: EDUFBA, p. 58-74, 2007. < Disponível em http://books.scielo.org Acesso em: $10 / 09 / 2013>$

SOUZA, Elizeu Clementino de. O conhecimento de si: estágio e narrativas de formação de professores. Rio de Janeiro: DP\&A; Salvador, BA:UNEB, 2006.

\footnotetext{
' Professor Adjunto do Departamento de Artes Visuais da Universidade de Brasília. E.mail: luizcpferreira@gmail.com
}

Recebido em: 24/12/2014

Aprovado em: 01/04/2015 